Estudios Constitucionales, Año 16, No 1, 2018 pp. 395-424

ISSN 07180195

Centro de Estudios Constitucionales de Chile Universidad de Talca

"Prejuicios y homosexualidad, el largo camino hacia la

adopción homoparental. Especial atención al caso colombiano"

Tania Bolaños Enríquez - Ariel Charry Morales

\title{
PREJUICIOS Y HOMOSEXUALIDAD, EL LARGO CAMINO HACIA LA ADOPCIÓN HOMOPARENTAL. ESPECIAL ATENCIÓN AL CASO COLOMBIANO*
}

\author{
PREJUdiCES AND HOMOSEXUALITY, THE LONG WAY TOWARDS THE LGBT \\ PARENTING. SPECIAL ATTENTION TO THE COLOMBIAN CASE
}

\author{
Tania Bolaños EnríQuez \\ Profesora Universidad Cooperativa de Colombia \\ taniagicela@hotmail.com \\ Ariel Charry Morales ${ }^{* * *}$ \\ Profesor Universidad Cooperativa de Colombia \\ arielcharry3@gmail.com
}

RESUMEN: El presente artículo aborda el tema de la discriminación generada por prejuicios hacia la población con orientación sexual e identidad de género no hegemónica, quienes en atención a las dinámicas sociales han tenido que reivindicar sus derechos en los estrados judiciales. Especialmente se concentra en la posibilidad de la adopción homoparental, considerando la adopción prima facie como un derecho de los niños, niñas y adolescentes que tiene, como efecto secundario, la posibilidad para hombres y mujeres, independientemente de su orientación sexual o de su identidad de género, de tener un hijo o hija y establecer asi una relación paterno filial protegida por el derecho.

PALABRAS CLAVE: Prejuicios, adopción, homosexualidad, familia, matrimonio homoparental.

ABSTRACT: This article addresses the issue of discrimination, which is generated by prejudices against the people with non-hegemonic sexual orientation or gender identities, who due the social dynamics have had to demand their rights in the courts. It specially focuses on the possibility of the adoption when both parents are of the same-sex (LGBT parenting), considering prima facie the adoption as a right of the children and teenagers, which entails as secondary effect the possibility for men and women, regardless of their sexual orientation or their gender identity, to have a son or a daughter, and so to establish a parent-child relationship protected by law.

KEYWORDS: Prejudices, adoption, homosexuality, family, same-sex marriage.

\footnotetext{
* Artículo recibido el 11 de noviembre de 2017 y aprobado el 10 de enero de 2018.

** Doctora y Magíster en Derecho de la Universidad de Heidelberg, Alemania, Abogada U. Externado. Líder del grupo de investigación La Minga e integrante del Grupo CIFAD de la Facultad de Derecho de la Universidad Cooperativa de Colombia. Correo electrónico: taniagicela@hotmail.com; tania.bolanos@ucc.edu.co.

*** Magíster en Filosofía U. Javeriana, Colombia, Filósofo U. Nacional de Colombia, Especialista en Docencia Universitaria (UCC), Licenciado en Ciencias Sociales y Económicas de la Universidad Libre de Colombia. Integrante del grupo de investigación Prometeo de la Facultad de Psicología de la Universidad Cooperativa de Colombia. Correo electrónico: arielcharry3@gmail.com; Ariel.charry@campusucc.edu.co.
} 


\section{INTRODUCCIÓN}

Los prejuicios son un elemento de la percepción social sobre las características o comportamientos de las personas y constituyen un recurso de economía cognitiva para juzgar y discriminar a los diferentes grupos sociales por razones de raza, sexo, origen, orientación política, religiosa u otros, generando actitudes de rechazo hacia ellos. Uno de los sectores en riesgo de vulneración de derechos, y que es víctima además de los prejuicios sociales, son las personas con orientación sexual e identidad de género no hegemónica. En los últimos años se han producido importantes avances jurídicos en cuanto a la protección de sus derechos propendiendo a una mayor igualdad en el ejercicio y goce de los mismos. Sin embargo el tema no deja de ser controversial, especialmente en regiones con fuerte arraigo judeocristiano, razón por la cual este artículo se presenta como un esbozo académico y científico que pretende explicar de dónde surgen los prejuicios y por qué deben ser superados tratándose de uno de los tópicos más críticos en la discusión, cual es la adopción homoparental.

Para ello se realizó una investigación cualitativa que parte de la posición inicial de Husserl de llevar a cabo una reflexión fenomenológica y de la que se conserva su impulso crítico y su radicalidad, pero que se asume desde el giro que realiza Heidegger de la fenomenología al abordarla como una filosofía de la vida o como una hermenéutica ${ }^{1}$, la razón de ello es porque se parte del mundo fáctico, del mundo real o de la existencia para terminar en el pensamiento reflexivo, puesto que la relación que se da entre el hombre (der Mann) con el mundo (die Welt) sólo es posible a través del comprender (verstehen), y la comprensión es una condición ontológica del hombre. Se quiere comprender el reclamo que realiza la población con orientación sexual e identidad de género no hegemónica a la sociedad para legitimar su condición de existencia en tanto ciudadanos y garantizado dicho reclamo desde lo jurídico. Heidegger hace referencia al hombre en tanto que está ahí (Dasein) y ese hombre ahí en el mundo como ser existencial constituye la preocupación del presente trabajo, particularmente de la población homosexual que se hace visible para pedir igualdad de derechos.

Siguiendo una metodología de análisis interpretativo y crítico que aborda el tema de la adopción de menores de edad por familias homoparentales a partir del hecho de la transformación de la familia, a través de la revisión documental de análisis de casos y estudios desde la psicología y el derecho, se responde a la

1 LEÓN (2009), pp. 272-273. 
pregunta sobre cuáles son los parámetros normativos que permiten la adopción homoparental y que priman sobre los prejuicios sociales. Para ello, el capítulo II, denominado prejuicios y homosexualidad, explica los estereotipos, las actitudes, su origen y funciones. Aborda desde la psicología social el proceso de aprendizaje y economía cognitiva que realiza el individuo, que le permite emitir juicios de valor -positivos o negativos, correctos o incorrectos- sobre otras personas y que tratándose de homosexuales, va ligado a las creencias y roles sociales imperantes, estimulando la violencia y generando discriminación. El acápite siguiente, a la luz del nuevo concepto de familia, presenta el matrimonio igualitario como uno de los desarrollos más recientes en el mundo moderno en cuanto al ejercicio del derecho a la igualdad. Esto obedece, entre otras cosas, a una profunda transformación sociocultural que reconoce que el concepto de familia no es monolítico por cuanto las formas de vida familiar pueden ser diversas como resultado del ejercicio y goce de derechos fundamentales entre los que se destacan la libertad y la igualdad. Finalmente el último capítulo se refiere a la adopción homoparental la cual se fundamenta en el interés superior del menor de edad más que en el derecho que puedan tener las personas para adoptar. En este punto, se presentan algunos avances normativos y jurisprudenciales que han impactado en el reconcomiendo de derechos a las personas con orientación sexual e identidad de género diversa en pro de evitar su discriminación, reivindicando el derecho de los niños, niñas y adolescentes a tener una familia y disfrutar de ella, punto que se consigna nuevamente en las conclusiones del artículo.

\section{Prejuicios y homoseXUALIDAD}

Como una característica propia de las personas, el prejuicio se camufla en la vida cotidiana de cada individuo, desplazándose dentro de todos los ámbitos sociales, y constituye una impresión negativa -rara vez positiva- que influye en la dinámica social de los seres humanos. Dichas impresiones representan estereotipos, de tal forma que los prejuicios son, "una actitud hostil o prevenida hacia una persona que pertenece a un grupo, simplemente porque pertenece a ese grupo, suponiéndose por lo tanto que posee las cualidades objetables atribuidas al grupo"2.

Los prejuicios no aparecen de la nada, se trata de un proceso complejo, estudiado particularmente por la psicología social. El ser humano como ser social, adelanta diferentes mecanismos para aprender, y es preciso que aprenda para

2 Allport (1971), p. 22. 
poder desenvolverse en el mundo. Las relaciones con otras personas y con otros contextos, en el marco de la dinámica de socialización en la que entran familias, instituciones y grupos sociales diversos, permite a las personas recoger gran cantidad de información que será procesada y servirá para emitir juicios, siendo un juicio un pensamiento en el que se afirma o se niega algo ${ }^{3}$. En esa interacción surge la cognición social.

Pero la cognición social no es neutral, esta cognición es permeada por tendencias, esquemas sociales, y atajos (heurística) para conocer rápidamente el ambiente social e inferir conclusiones ${ }^{4}$.

La cognición social permite la formación del autoconcepto, simultáneamente lleva a categorizar el entorno, que al simplificarlo, hace más fácil la relación con el mismo. De esta manera se rotula a las personas a partir de las impresiones que circulan en el ambiente, aceptando lo que confirma dicha impresión y rechazando lo que la contradiga ${ }^{5}$. Las personas, al entrar en contacto con el entorno social, se forman impresiones sobre los demás y recurren a estrategias de economía de esfuerzo cognitivo para conocer el ambiente que les rodea ${ }^{6}$. Una de las consecuencias de dicho conocimiento es la formación de actitudes, que no son más que sentimientos a favor o en contra de personas o de cosas 7 . Esto quiere decir que las actitudes son aprendidas. Este aprendizaje puede ser por asociación, por condicionamiento instrumental o, por observación ${ }^{8}$. En lo que respecta al caso de aprendizaje por asociación, los infantes pueden terminar imitando los gestos de desagrado que los padres realizan cada vez que se encuentran frente a una persona de un sector social determinado. De otra parte, el condicionamiento instrumental o el aprender a mantener los puntos de vista correctos se interioriza por los menores cuando son recompensados por sus padres al manifestar un acuerdo con ellos.

3 Gutiérrez SÁeZ afirma que "juzgar es lo mismo que afirmar o negar algo" (1988, p. 139); por su parte IBARRA BARRÓN en el mismo sentido dice que "En primer lugar debemos saber que el juicio es la segunda operación lógica de la mente. Y su definición etimológica viene del verbo latino Judicare, que significa juzgar". Y un poco más adelante agrega "(...) nuestra inteligencia da su sentencia sobre sí misma, sobre su propio producto; afirma o niega respecto a su propio desarrollo, representado en el predicado” (1994, p. 137).

4 Rodríguez et al. (2008), p. 134.

5 Rodríguez et al. (2008), pp. 150-152.

6 Rodríguez et al. (2008), p. 95. Baron y Byrne (2005), pp. 99-100.

7 Baron y Byrne (2005), pp. 125-128.

8 BarOn y BYrne (2005), pp. 125-127. 
Finalmente, si la cognición social se deriva del aprendizaje observacional, será el ejemplo el camino para adquirirlo9.

Así las cosas, las actitudes permiten que la persona exprese valores y creencias centrales que afirman o reafirman su identidad; proporcionan confianza a las personas quienes están convencidas de la validez de su actitud y piensan, por lo tanto, que los demás deberían actuar como ellos, haciendo que rechacen información contraria; y, finalmente, las actitudes motivan a la persona, ya que ésta, al buscar producir una buena impresión en los demás, se esfuerza en argumentar sus creencias, lo que las refuerza, haciendo más difícil que cambie sus actitudes ${ }^{10}$. Entonces, las actitudes cumplen muchas funciones y "estas funciones a su vez pueden moldear de manera importante el impacto de las influencias que ejercen sobre el procesamiento de la información social"11.

Las funciones de la actitud permiten deducir sus tres componentes, estos son, el cognoscitivo, el afectivo y el relativo a la conducta ${ }^{12}$. El componente cognoscitivo está directamente relacionado con la representación que tiene el sujeto del objeto, lo que da como consecuencia una actitud de tal forma que, cuando la representación es vaga, su afecto hacia el objeto será poco intenso y cuando la representación es errónea su afecto no será alterado, corresponda o no a la realidad. Esta última posibilidad puede ser percibida con claridad en el caso del prejuicio ${ }^{13}$.

El componente afectivo es el sentimiento a favor de un objeto social específico y es la característica más visible de la actitud; sin embargo, no toda opinión o creencia está cubierta por el componente afectivo, solamente cuando una persona se emociona defendiendo una idea determinada en un debate aflora dicho elemento. Por su parte, el componente conductual hace referencia a la acción que motiva la actitud, es decir, es el comportamiento congruente que resulta de la cognición y el afecto de una condición dada, aunque no siempre se presenta una coherencia directa entre estos tres componentes. "Con frecuencia encontramos personas que se dicen católicas, protestantes o judías, pero que no se conducen de acuerdo con las prescripciones de dichas religiones"14.

\footnotetext{
9 Baron y Byrne (2005), p. 127.

10 Baron y Byrne (2005), p. 147.

11 Baron y Byrne (2005), p. 132.

12 Rodríguez et al. (2008), pp. 87-89.

13 Rodríguez et al. (2008), p. 87.

14 Rodríguez et al. (2008), p. 89.
} 
Se puede deducir que entre actitud y conducta existe una estrecha relación, y esta relación no es de ninguna manera lineal; de tal forma que las situaciones reales conllevan a que en unos casos las actitudes determinen la conducta y, en otros casos, la conducta o el comportamiento determina las actitudes. En este sentido, "no sólo nuestras actitudes internas nos guian, sino también la situación que enfrentamos"15, de hecho, la influencia social puede inducir a olvidar las convicciones más arraigadas ${ }^{16}$.

Uno de los prejuicios presentes en la sociedad se relaciona con la orientación sexual y de género de las personas, que ha sido reforzado por la tipificación del rol sexual. En la sociedad se han establecido estereotipos sexuales que producen una imagen de un grupo social y que exigen roles específicos de acuerdo con el sexo de cada persona. En este orden de ideas, ligado a creencias sociales o psicológicas presentes en un grupo determinado, se enseña a las niñas, niños y adolescentes cuáles son las formas adecuadas de comportamiento según el sexo y el rol que cada uno debe cumplir en la sociedad ${ }^{17}$.

Ahora bien, desde la realidad del sexo tenemos que la orientación del deseo sexual puede dar origen a múltiples alternativas tanto para las mujeres como para los varones: personas heterosexuales, homosexuales, bisexuales, pansexuales, transexuales, etcétera ${ }^{18}$. La orientación sexual más difundida tradicionalmente es la heterosexual, en la que se relacionan dos personas de sexo opuesto biológicamente hablando. Pero no siempre fue así, "las relaciones sexuales entre personas del mismo sexo eran comunes en la Grecia clásica. Los filósofos de aquellas épocas y latitudes las practicaban y defendían teóricamente" ${ }^{19}$; más aún, la palabra homosexualidad sólo aparece en 1869 acuñada por Karl María Kertbeny cuando se pronunció en contra de un artículo del código penal prusiano que condenaba y criminalizaba la relación sexual entre hombres ${ }^{20}$. Antes de dicha fecha es técnicamente impreciso hablar de homosexualidad ya que la sociedad griega y romana antiguas manejaban categorías sexuales diferentes a las nuestras, e incluso los ritos homosexuales

15 Myers (2005), p. 139.

16 Myers (2005), p. 139.

17 Bonilla (2004), p. 7. Garzón-Segura (2015), pp. 30-45.

18 Fernández (2004), p. 47.

19 Méndez (2007), pp. 47-48.

20 Mondimore (1998), p. 21; Baile (2008), pp. 28-29. 
constituían el inicio de la masculinidad para pueblos aborígenes como las tribus ancestrales de la isla de Papúa-Nueva Guinea ${ }^{21}$.

Ahora bien, tanto la definición de la identidad sexual, esto es el auto-reconocimiento en un género particular, como la definición de su orientación sexual, es decir, de la inclinación afectiva hacia otros ${ }^{22}$, compete exclusivamente a la esfera íntima de cada individuo y están protegidas por la Constitución y la Ley pues forman parte de su dignidad así como del ejercicio de su libertad y autonomía ${ }^{23}$. Entonces, las personas con orientaciones sexuales e identidades de género no hegemónicas cuentan con protección constitucional reforzada, de un lado, por el derecho al libre desarrollo de la personalidad (que involucra la libertad y autonomía) y del otro, por la prohibición de discriminación como consecuencia de su condición u orientación sexual (que implica la igualdad de trato). La noción de igualdad es inseparable de la dignidad y prohíbe la posibilidad de brindar un trato discriminatorio u hostil a una persona o grupo por considerarla inferior frente a otro, garantizando así el goce de derechos en igualdad de condiciones ${ }^{24}$. De hecho, en el espacio interamericano, la OEA desde el 2008 ha aprobado cuatro resoluciones respecto de la protección de las personas contra tratos discriminatorios basados en su orientación sexual e identidad de género, exigiendo a los Estados Parte, la adopción de medidas concretas para proteger a esta población de actos discriminatorios (AG/RES 2653/11; AG/RES 2600/10; AG/RES 2504/09; AG/ RES 2435/08).

El comité de derechos humanos del pacto internacional de derechos civiles y políticos ha definido la discriminación como:

"toda distinción, exclusión, restricción o preferencia que se base en determinados motivos, como la raza, el color, el sexo, el idioma, la religión, la opinión política o de otra índole, el origen nacional o social, la propiedad, el nacimiento o cualquier otra condición social. Y que tengan por objeto o por resultado anular o menoscabar el reconocimiento, goce o ejercicio, en condiciones de igualdad, de los derechos humanos y libertades fundamentales de todas las personas" 25 .

21 Gilbert (2006), pp. 35-36. Franke (2007), p. 18.

22 Corte ConstitucionaL, T-565/13.

23 Corte ConstitucionaL, T-565/13.

24 Corte IDH, Serie C No 254, para 79, de 24 de febrero de 2012.

25 U.N. Doc. CCPR/C37 (1989) OG 18. 
Si bien la orientación sexual e identidad de género no están expresamente incluidas en la definición, los tribunales internacionales y los comités de Naciones Unidas han reconocido que estas categorías pueden ser incluidas en la expresión $o$ cualquier otra condición social o que bien, la categoría sexo las incluye ${ }^{26}$. Asimismo, la Asamblea General de las Naciones Unidas adoptó en 2008 una Declaración "sobre derechos humanos, orientación sexual e identidad de género" en la que expresamente hace referencia a que el principio de no discriminación es aplicable a todas las personas independientemente de su orientación sexual o identidad de género ${ }^{27}$.

En consecuencia, la discriminación es la conducta, actitud o trato -consciente o inconsciente- tendiente a dominar, anular o ignorar a una persona apelando a prejuicios o preconcepciones sociales o personales y conlleva a la violación de derechos fundamentales ${ }^{28}$. Múltiples ideas, impresiones, creencias o experiencias pueden conducir a la formación de prejuicios, de opiniones generalizadas inclusive erróneas, que puede degenerar en discriminación o conducta hostil hacia los miembros de un grupo determinado ${ }^{29}$. De hecho, la discriminación histórica que han sufrido las minorías sexuales ha generado que sean sujeto de violencia física con altos niveles de ensañamiento y crueldad, misma que ha recibido el nombre de violencia por prejuicio ${ }^{30}$. De allí que los Estados deban adoptar medidas para erradicar el estigma y los estereotipos negativos contra este grupo de la sociedad, los cuales refuerzan la discriminación y la violencia contra ellos ${ }^{31}$.

Frente a los prejuicios regularmente el que juzga no tiene las herramientas necesarias para argumentar la opinión que emite, pues el prejuicio pertenece a la esfera de lo no racional, lo que dificulta que sea desmentido mediante argumentos racionales $^{32}$. Un prejuicio se resiste a todo tipo de razón, lo emocional se pone de manifiesto y se rechaza todo tipo de argumento ${ }^{33}$.

\footnotetext{
26 U.N. Doc. CCPR/C50/D/488/1992 (1994) párr. 8.7; U.N.Doc. CCPR/C89/D71361/2005, párr. 7.2; TEDH, Solicitud No 33290/96 (1999) párr. 28; TEDH, Solicitud No 7205/07 (2010) párr. 57.

$27 \mathrm{~A} / \mathrm{Res} / 63 / 635$ (2008).

28 Corte ConstitucionaL, T-098/94; Baron y Byrne (2005), p. 123; Myers (2005), p. 143; Rodríguez, et al. (2008), p. 93.

29 ACUÑa-Ruiz y Oyuela (2006), pp. 60 y 63.

30 CIDH (2015), p. 11.

31 CIDH (2015), p. 16.

32 Воввіо (2010), p. 184.

33 Allport (1971), p. 24.
} 
Las personas cultivan varios tipos de prejuicios (económico, social, político, religioso, sexual, profesional, etcétera), que pueden ser directamente reforzados por los medios de comunicación, los que por ejemplo son "una de las fuerzas más poderosas en la transmisión y el mantenimiento de los estereotipos sexuales tradicionales"34. Por ello, la Comisión Interamericana de Derechos Humanos ha examinado el importante papel que juegan los medios de comunicación en la implementación de estrategias para prevenir y combatir la violencia por prejuicio y el discurso de odio contra las minorías sexuales y recomendó a los Estados "[e]stimular la adopción de códigos profesionales voluntarios de conducta para los medios y periodistas, en tanto éstos pueden jugar un rol fundamental en la lucha contra la discriminación y la promoción de los principios de igualdad"35.

Sin embargo, contrarrestar la discriminación contra la población con orientación sexual e identidad de género no hegemónica es un proceso de cambio que toma tiempo porque a pesar de que la ley y los órganos internacionales la prohíban, es necesario que la sociedad asimile e interiorice mentalmente las políticas públicas al respecto para que la norma sea coherente con la realidad y ésta con aquella ${ }^{36}$.

\section{UN NUEVO CONCEPTO DE FAMILIA: EL MATRIMONIO IGUALITARIO}

La familia es el elemento natural y fundamental de la sociedad y todas las personas, hombres y mujeres, sin restricción alguna por motivos de raza, nacionalidad o religión tienen derecho a fundar una ${ }^{37}$; en consecuencia, las formas de vida familiar pueden ser diversas y se adaptan al contexto sociocultural vigente. La familia ha sido definida como "aquella comunidad de personas emparentadas entre sí por vínculos naturales o jurídicos, que funda su existencia en el amor, el respeto y la solidaridad, y que se caracteriza por la unidad de vida o de destino que liga íntimamente a sus miembros o integrantes más próximos" 38 , y tradicionalmente tiene funciones económicas, conferidora de status social, educativa, religiosa, recreativa, de preservación de la especie, de socialización de las nuevas

\footnotetext{
34 Hogg y Vaughan (2010), p. 356.

35 CIDH (2015), p. 298.

36 Albarracín y Noguera (2007), pp. 7-9; Vargas (2013), pp. 30-33.

$37 \mathrm{~A} / \mathrm{Res} / 3 / 217^{\mathrm{a}}$ (1948), art. 16.

38 Corte ConstitucionaL, C-271/03.
} 
generaciones y canalización de afectos ${ }^{39}$. No obstante, las funciones tradicionales de la familia han sido asumidas o compartidas por instituciones más especializadas, así por ejemplo la función económica que cumplía la familia tradicional rural, ha pasado -aunque no exclusivamente- a la empresa industrial moderna; asimismo, las funciones de aprendizaje de un oficio o profesión y de la educación en general ha pasado a la escuela y otras instituciones de educación, siendo la familia encargada particularmente de la gratificación afectiva de sus integrantes y de la socialización de las nuevas generaciones acorde con la cultura vigente para que puedan ser integrados a la sociedad ${ }^{40}$. De allí que el papel de los padres es educar y formar a los hijos, donde el ejemplo vale más que la palabra, y obrar de tal forma que establezcan la justa medida de todas las cosas propias de la vida para forjar una existencia satisfactoria.

Ahora bien, la familia como grupo social ha cambiado su estructura con el paso del tiempo, incorporando nuevas costumbres y dinámicas sociales que modifican su composición. Precisamente, uno de los efectos del reconocimiento del matrimonio civil entre parejas del mismo sexo, es la constitución formal de una familia y con él los deberes de fidelidad y socorro mutuo, la modificación del estado civil, el surgimiento de la sociedad conyugal, el ingreso al orden sucesoral, la posibilidad de suscribir capitulaciones, que pueden invocar los beneficios tributarios por tener cónyuge o compañero permanente y, de llegar la nueva familia a establecer su residencia en otro país, las respectivas autoridades deberán brindarles la protección legal que tienen los cónyuges ${ }^{41}$. Asimismo, las relaciones entre los miembros de la familia se han democratizado y son más igualitarias que antiguamente ${ }^{42}$.

Hablar de la familia hoy en día, como lo afirma Mujika Flores (2005), implica muchas posibilidades ya que ésta no se reduce al núcleo familiar de antaño (padres heterosexuales e hijos), no hay un solo modelo de familia originado exclusivamente por el rito del matrimonio, sino que la necesidad de los hechos ha llevado a hablar de hogares donde la madre o el padre es cabeza de familia (familia monoparental), está la familia adoptiva, familia sin hijos, familia de padres o madres separados o divorciados, familias ensambladas que se conforman cuando uno de

39 Oliva y Villa (2014), pp. 13-15; De Pablo (1976), p. 345.

40 De Pablo (1976), p. 345; Valdivia 2008, p. 24.

41 Corte Constitucional, SU-214/16.

42 De Pablo (1976), p. 346; Gutiérrez y Osorio (2008), p. 118. 
los cónyuges o compañeros trae a sus hijos previos a la nueva unión, familia de padres y madres de distintas etnias o culturas, la familia homoparental, familia de crianza, entre otras.

Los elementos que constituyen la unidad familiar en el espacio y tiempo se desglosaron y no por ello desapareció la familia, lo que desapareció fue su concepto monolítico no siendo la heterosexualidad una característica exigible a todo tipo de familia como tampoco lo es más la consanguinidad. Ya hace un par de décadas que terminó el prejuicio que recaía sobre las mujeres separadas o divorciadas y con hijos, las que difícilmente se volvían a organizar o a tener un nuevo hogar ya que se les descalificaba socialmente ${ }^{43}$ y las personas con orientaciones sexuales e identidades de género no hegemónicas se empoderaron y reconocieron su identidad, todo lo cual ha contribuido en la ampliación del concepto de familia. Así se rebasa lo biológico en la conformación familiar y se da paso a la familia diversa que se adapta al contexto social ${ }^{44}$.

En el campo interamericano igualmente, la Convención Americana protege como familia todos los lazos conformados por matrimonio o de hecho donde las partes tengan vida en común. No se protege entonces, un solo concepto cerrado y tradicional de familia, pues ello implicaría sostener una percepción "limitada y estereotipada del concepto de familia que no tiene base en la Convención al no existir un modelo específico de familia (la familia tradicional)" 45 .

Las personas nacen en el seno de una sociedad previamente establecida, la cual cuenta con costumbres y valores que serán asumidos como propios por los individuos y que pueden variar de una sociedad a otra. Sin embargo, tales valores junto con las leyes impartidas por las instituciones y el Estado, determinan la convivencia social. De hecho, en algunos casos las normas jurídicas tienen en cuenta la moral vigente para señalar las consecuencias sobre diferentes actos. "Hay siempre una moral social, que es la que prevalece en cada pueblo en su propia circunstancia" 46 .

En las sociedades en general se busca un ordenamiento y un orden social que permita a sus integrantes vivir con la mayor satisfacción posible, donde el Estado está en la obligación de brindar las condiciones y oportunidades que sean

43 UNICEF, (2003).

44 Corte ConstitucionaL, C-577/11.

45 Corte IDH, Serie C No 254, para. 145, de 21 de noviembre de 2012.

46 Corte Constitucional, C-224/94. 
del caso, para que sus ciudadanos logren sus metas, crezcan como personas y se sientan realizados en las diferentes etapas de su ciclo vital. En esta estructuración existe una intención clara que permite mantener un orden establecido en cuyo propósito cumplen una función determinante la religión y la educación ${ }^{47}$. En el caso de Colombia la iglesia católica y los claustros educativos han jugado un papel protagónico en la adopción e interpretación de las normas morales predominantes y en las prácticas que contienen las buenas costumbres abrigando una importante vocería y gozando de un eco significativo en la sociedad, que le ha permitido, especialmente a la iglesia, participar o incidir activamente en la redacción y aprobación de leyes, en las negociaciones de paz con grupos armados organizados al margen de la ley y en la regulación de instituciones como la educación y la familia ${ }^{48}$.

Así por ejemplo, para la Iglesia católica la relación de pareja que se considera legítima por designio divino es la que se da entre un hombre y una mujer, lo cual se respalda con la Biblia en el libro del Génesis con la aparición de Adán y Eva. Ya de entrada cualquier otro tipo de relación sería aberrante, "por principio, toda unión sexual que no tenga relación directa con la procreación y que no acontezca en el ámbito del matrimonio heterosexual, será rechazada y calificada como antinatural" 49 ; en consecuencia, las manifestaciones de afecto y de amor de pareja se deben dar entre personas de sexo opuesto. Con relación al matrimonio, en la celebración de la Fiesta de la Santa Familia de Nazaret de 2009, en la Plaza de San Pedro, se dijo a los feligreses: "uno de los mayores servicios que los cristianos podemos prestar a nuestros semejantes es ofrecerles nuestro testimonio sereno y firme de la familia fundada en el matrimonio entre un hombre y una mujer, salvaguardándola y promoviéndola" 50 .

Adrian Schenker (2008), especialista en el tema religioso, considera que una de las razones de la prohibición de las relaciones homosexuales por parte de Moisés es la de evitar la fecundidad inútil, pues la principal razón de una unión de pareja de sexos opuestos es básicamente la procreación. De acuerdo con Schenker, la razón por la cual la iglesia católica no aprueba la homosexualidad se debe a lo inapropiado de tener relaciones sexuales que no tengan como finalidad

\footnotetext{
47 Urraco-Solanilla y Nogales-Bermejo (2013), pp. 155-156.

48 Otero (2008), p. 1.

49 Martínez (2012), p. 25.

50 Benedicto XVI, domingo 27 de diciembre de 2009.
} 
la fecundación, de esta manera se descarta el placer, que incluso se condena por pecaminoso. El Papa Francisco también mantiene una posición conservadora frente al matrimonio y la familia al considerar que:

"Nadie puede pensar que debilitar a la familia como sociedad natural fundada en el matrimonio es algo que favorece a la sociedad (...) Debemos reconocer la gran variedad de situaciones familiares que pueden brindar cierta estabilidad, pero las uniones de hecho o entre personas del mismo sexo, por ejemplo; no pueden equipararse sin más al matrimonio" ${ }^{\prime 1}$.

Esta misma concepción ha tenido repercusiones jurídicas haciendo que el legislador, y por lo tanto los Estados, denieguen la legitimidad del matrimonio de parejas del mismo sexo reforzando así el prejuicio que recae sobre la comunidad con orientación sexual e identidad de género no hegemónica ${ }^{52}$. El Código Civil colombiano que data de 1873, en su artículo 113 define el matrimonio como "un contrato solemne por el cual un hombre y una mujer se unen con el fin de vivir juntos, de procrear y auxiliarse mutuamente" y se requirió del esfuerzo y perseverancia de varias organizaciones de la sociedad civil para hacer valer como matrimonio, las uniones del mismo sexo aprobadas desde el 200753. Sólo hasta abril de 2016 la Corte Constitucional Colombiana mediante Sentencia de Unificación 214, como respuesta a varios amparos promovidos por la población con orientación sexual e identidad de género no hegemónica, expresamente reconoció que, si bien la Constitución consagraba el matrimonio como el vínculo entre un hombre y una mujer, en aplicación de los principios de dignidad humana, base fundamental de los derechos humanos, de la libertad individual y la igualdad, no es dable excluir la unión de parejas del mismo sexo como matrimonio. Al tenor la Corte dijo:

"Aunque el artículo 42 de la Constitución establece, de manera expresa, que el matrimonio surge del vínculo entre un hombre y una mujer, de esta descripción normativa mediante la cual se consagra un derecho a favor de las personas heterosexuales, no se sigue que exista una prohibición para que otras lo ejerzan en igualdad de condiciones. Instituir que los hombres y las mujeres puedan casarse entre sí, no implica que la Constitución excluya la posibilidad de que este vínculo se celebre entre mujeres

51 Papa Francisco (2016), p. 45.

52 Eskridge (1993), pp. 1419-21.

53 Corte Constitucional C-075/07; ver C-577/2011. 
o entre hombres también. Esto se debe a que en la hermenéutica constitucional, la enunciación expresa de una categoría no excluye la existencia de otras, incorporando per se la regla de interpretación "inclusio unius est exclusio alterius", pues la Carta Política no es una norma general escrita en lenguaje prohibitivo" 54 .

Así pues, la Corte resalta que la norma Superior ha sido escrita en un lenguaje deóntico de valores, de principios y derechos fundamentales, lo que permite que se realice una interpretación sistémica de éstos para comprender el contenido de sus normas.

La anterior interpretación responde al hecho de que el derecho no es letra muerta y que por el contrario se adapta a la realidad cambiante de las sociedades, se trata de un derecho viviente que no admite, por discriminatorio, el trato diferenciado que recibía la unión de dos personas, fundado en su orientación sexual o identidad de género; situación que contradecía los más altos principios del derecho internacional de los derechos humanos reconocidos desde antaño con la Declaración Universal de los Derechos Humanos cuyos artículos $1^{\circ}$ y $2^{\circ}$ se refieren a la igualdad de trato para todas las personas, pues nacen libres e iguales y por lo tanto prohíbe la discriminación en el reconocimiento de derechos pese a las diferencias que puedan existir.

En consecuencia, una interpretación sistemática del derecho viviente que tenga en cuenta la realización y garantía de derechos para las minorías, impide tratar de manera diferenciada el matrimonio según las partes que lo conforman, pues se enviaría a la sociedad un mensaje equivocado, cual es la existencia de ciudadanos de segunda clase, que implicaría a la existencia de dos clases de matrimonio, lo cual quebranta los derechos a la libertad, la dignidad y la igualdad. Expresamente la Corte Constitucional en esta paradigmática sentencia de Unificación, con la que pretende ponerle coto a la discusión jurídica sobre la materia en Colombia, destacó que " $[\mathrm{u}] \mathrm{n}$ sistema constitucional y democrático no admite la existencia de dos categorías de ciudadanos: unas mayorías que gozan del derecho a contraer matrimonio civil y unas minorías que están injustamente desprovistas de éste" 55 .

No obstante lo anterior, la influencia de los valores judeocristianos en el derecho se ha dejado notar en Colombia, pues, pese a que la Corte Constitucional, máximo garante de los derechos fundamentales en el país, ha reconocido la validez del matrimonio entre personas del mismo sexo y ha exhortado al Congreso

54 Corte Constitucional SU-214/16.

55 Corte Constitucional SU-214/16. 
de la República desde el año 2011 para que regule el tema, hasta la fecha no se ha logrado saldar dicha deuda y los 18 proyectos de ley presentados y discutidos sobre el particular desde 1999, no han logrado materializarse en una norma, razón por la cual la regulación de las relaciones jurídicas derivadas de las diversas modalidades de uniones de convivencia de las parejas del mismo sexo, continúa siendo una omisión legislativa ${ }^{56}$.

Si bien las parejas de mismo sexo no se diferencian materialmente de parejas heterosexuales, y por lo tanto deberían recibir el mismo tratamiento legal que éstas, en la mayoría de los países sólo se les ha permitido obtener, sobre esta base, los mismos beneficios y derechos en seguridad social o civiles que las parejas heterosexuales, pero no ha sido suficiente para que su unión se considere como matrimonio, en especial argumentado que la definición del matrimonio en sí misma, moral y prácticamente, requiere de un hombre y una mujer ${ }^{57}$. Este tipo de oposiciones al matrimonio entre personas del mismo sexo, por lo general, tiene su fundamento más que en una lógica interna, en actitudes culturales basadas en la forma como se ha construido la sociedad perpetuadas por los prejuicios. Recuérdese como años atrás las personas afro y las blancas tenían prohibido contraer matrimonio entre sí, prohibición que hoy en día no es posible concebir ${ }^{58}$.

La autonomía que tienen todas las personas de contraer matrimonio es un predicado de la dignidad humana, es por ello que sólo los impedimentos derivados de la presencia de ciertos grados de consanguinidad, edad, ausencia de consentimiento libre o existencia de otro vínculo matrimonial son admisibles para limitar el derecho a contraer matrimonio ${ }^{59}$. En Latinoamérica, México desde el 2009, Uruguay desde el 2013, Argentina desde el 2010, Brasil desde el 2013 y Colombia desde el 2016 reconocen la legalidad del matrimonio de parejas del mismo sexo, pero desde tiempo atrás habían reconocido ya las uniones del mismo sexo sin darles el nombre de matrimonio ${ }^{60}$.

En Canadá, el Gobierno Federal expidió en el año 2005 la Ley C-38 en la que redefine el matrimonio catalogándolo como una unión legal entre dos personas, legalizando así el matrimonio entre personas del mismo sexo cuya prohibición vul-

\footnotetext{
56 Corte Constitucional SU-214/16.

57 ESKRIDGE (1993), pp. 1423 y 1428.

58 Van Der Walt y Basson (2015), pp. 2-3; Eskridge (1993), pp. 1423-25.

59 Corte Constitucional SU-214/16.

60 Ver Corte IDH, Serie C No 322, párr. 113-16, de 21 de noviembre de 2016.
} 
neraba el derecho a la igualdad previsto en la Constitución, modificación derivada de las consideraciones de la Corte Suprema que reconocían el matrimonio como una institución fundamental, que no podía por lo tanto privársele a las personas homosexuales ${ }^{61}$. Razonamiento similar fue realizado por la Corte Sudafricana que llevó al Parlamento en 2006 a aprobar el acto de unión civil mediante el cual expresamente determina que la unión civil voluntaria entre dos personas puede solemnizarse a través del matrimonio.

Por su parte el Tribunal Europeo de Derechos Humanos ha manifestado recientemente que si bien las parejas del mismo sexo tienen derecho a gozar la protección del Estado, que puede ser brindada a través de diferentes formas jurídicas, no es obligación de los Estados regular el matrimonio de personas del mismo sexo. Según el Tribunal, esta decisión recae exclusivamente en el margen de apreciación nacional ${ }^{62}$ y así lo han hecho entre otros, Bélgica en el 2003, España en el 2005, Noruega en el 2008, Suecia en el 2009, Portugal en el 2010, Francia en el 2013, Alemania en el 2017.

En suma, el reconocimiento del matrimonio de personas del mismo sexo responde al hecho que el matrimonio es un rito ligado a la dignidad humana y como tal un derecho fundamental, mediante él "dos personas pueden encontrar juntas otras libertades, como la expresión, la intimidad y la espiritualidad"63 independientemente de su orientación sexual y así debe ser establecido por las legislaciones, pues aunque la ley se apoye en criterios de moral pública, si ésta desconoce los principios superiores del Estado Social y Democrático de Derecho, que se funda en el respeto por los derechos humanos, sería inconstitucional acatarla.

\section{ADOPCIÓN DE NIÑOS Y NIÑAS POR FAMILIAS HOMOPARENTALES}

Como se ha mencionado con antelación, la homosexualidad es una condición de la persona que implica una elección de estilo de vida ${ }^{64}$ y compete a la esfera íntima del individuo en ejercicio de su autonomía la cual, al igual que otros gustos y preferencias del ser humano, se va descubriendo con la experiencia y está determinada por múltiples factores, especialmente hormonales, genéticos y de

61 Supreme Court, 2004 SCC 79, de 9 de diciembre de 2004.

62 Tedh, Solicitud No 40183/07, párr. 48, de 9 de junio de 2016.

63 Us Supreme Court, 570 US, de 26 de junio de 2013.

64 Corte Constitucional, T-101/98. 
comportamiento $^{65}$. En ese sentido, no se puede atribuir a la familia la causa de la heterosexualidad, la homosexualidad o la bisexualidad. Lo que sí se puede decir es que la familia, como primera red social con la que cuentan los seres humanos, influye en la manera como se siente consigo mismo la persona cuando se da cuenta de que su deseo erótico y sexual está dirigido hacia personas de su mismo sexo ${ }^{66}$. De hecho, la no aceptación en la familia, conlleva mayor vulnerabilidad para la persona y desprotección ante los eventuales peligros de la sociedad ${ }^{67}$.

Ahora bien, respecto de los padres, el impacto de su homosexualidad en los hijos no se ha establecido de manera contundente en el ámbito científico. De acuerdo con el meta-análisis realizado por Bertuzzi (2007) lo que queda claro al respecto, es que las investigaciones realizadas por reconocidos autores (entre ellos las de Golombok y Tasker, Charlotte Patterson, Anderssen y Cols., Allen y Burell, Goodman y Cols., Belcastro y Cols., Cameron y Cameron) no arrojan resultados significativos; algunos de estos estudios no demuestran la existencia de efectos adversos en la calidad del cuidado de los hijos por parte de madres lesbianas o diferencias de crianza con relación al bienestar emocional y la orientación sexual por parte de padres homosexuales (hombres y mujeres) en comparación con los hijos de padres heterosexuales.

Existen múltiples y variadas formas para que las personas con orientación sexual e identidad de género no hegemónicas sean padres, aspecto cada vez más recurrente en las sociedades occidentales; por lo general, la mayoría de los hombres gay que son padres, lo hicieron mediante relaciones heterosexuales previas o mediante la donación de esperma a mujeres lesbianas ${ }^{68}$; las mujeres lesbianas gracias al desarrollo de la ciencia y la tecnología han podido disfrutar de la maternidad sin necesidad de renunciar a su homosexualidad ${ }^{69}$; pero con la eliminación de barreras legales, también se ha abierto paso la posibilidad para la adopción. Sin embargo, la heteronormatividad sigue siendo la regla general para autorizar la adopción de niños y niñas limitando por años esta posibilidad a las personas homosexuales en atención al prejuicio que les acompañaba, siendo la vía judicial la utilizada para cambiar los paradigmas sociales.

\footnotetext{
65 Ardila (2008), p. 61.

66 VARGAS et al. (2011), p. 59.

67 Antezana (2007), p. 32.

68 Riggs y Due (2014), p. 289.

69 Mujika (2005), pp. 6 y 9.
} 
Antes de abordar el tema de la adopción homoparental es preciso centrarse en la adopción como institución jurídica, su objeto y fin de modo que se pueda comprender cuál es su núcleo esencial, sin hacer todavía distinción respecto de las personas que solicitan la adopción. Así pues la adopción se define como "un acto voluntario y libre que crea, fuera de los vínculos de sangre, un vínculo de filiación entre dos personas"70, constituye en sí mismo "una medida de protección a través de la cual, bajo la suprema vigilancia del Estado se establece de manera irrevocable la relación paterno-filial entre personas que no la tienen por naturaleza" 71 y tiene por fin dar progenitores al menor de edad que carece de ellos, o que, aún teniéndolos no le ofrecen la atención, protección o los cuidados que requiere ${ }^{72}$. En sus orígenes, la adopción se consideró como un derecho del adoptante y no del adoptado y fue sólo a partir de las reformas hechas al Código de Napoleón que se realizó un primer acercamiento al carácter asistencial de la adopción en el interés de la persona adoptada ${ }^{73}$, lo que a la postre permitiría comprender la adopción como una "medida de protección en situaciones dramáticas para los menores de edad, como el abandono por parte de las familias biológicas (...) y en casos más complicados maltratados o abusados por los padres naturales y/o allegados"74.

A lo largo del siglo XX en la comunidad internacional se fue fortaleciendo la necesidad de proteger legalmente a los niños y niñas, razón por la cual se expidieron convenciones tendientes a garantizar los derechos de la infancia, las cuales tuvieron efectos sobre la institución de la adopción, entre los que se destaca la Convención Interamericana sobre Conflictos de Leyes en Materia de Adopción de Menores de 1984, la Convención sobre los Derechos del Niño de 1989 y el Convenio de La Haya sobre Protección del Niño y Cooperación en Materia de Adopción Internacional de 1993. De estas convenciones sobresale el abandono del enfoque adulto céntrico en el que las necesidades y bienestar del niño estaban supeditados a la familia biológica para dar paso a la corresponsabilidad del Estado y la familia y al reconocimiento de necesidades y derechos específicos de la infancia ${ }^{75}$. Precisamente, la Convención de Derechos del Niño determina en

70 Mazeaud et al. (1976), p. 553.

71 Gómez (1992), p. 288.

72 Bossert y Zannoni (2004), p. 481.

73 Rouast (1953), pp. 255-256.

74 Matarazzo (2016), p. 412.

75 Alonso (2014), pp. 289 y 92. 
su artículo 21 que "[l]os Estados Partes que reconocen o permiten el sistema de adopción cuidarán de que el interés superior del niño sea la consideración primordial". Así las cosas, cuando se trata de adopción, la atención recae sobre el menor de edad y no sobre el adoptante.

Siendo el interés superior del niño un principio y un mandato para las instituciones del Estado a la hora de garantizar sus derechos, es menester abordar este concepto, consagrado en el artículo $3^{\circ}$ de la citada convención y que irradia los ordenamientos jurídicos internos mediante el cual se transforma la concepción clásica de los menores como incapaces para permitirles su involucramiento en la toma de decisiones que les conciernen. "De esta manera de ser sujetos incapaces con derechos restringidos y hondas limitaciones para poder ejercerlos pasaron a ser concebidos como personas libres y autónomas con plenitud de derechos, que de acuerdo a su edad y a su madurez pueden decidir sobre su propia vida y asumir responsabilidades" 76 .

El principio de prevalencia del interés superior del niño implica que se debe tomar en cuenta todas las consideraciones que faciliten el desarrollo armónico de su personalidad, que le permitan crecer en un medio familiar, en un clima de felicidad, amor y comprensión ${ }^{77}$. Lo anterior debido a que este principio se funda en la dignidad humana que exige que se garantice cuidados y se brinde medidas especiales de protección a los niños para que se desarrolle y logre el aprovechamiento pleno de sus potencialidades ${ }^{78}$. La aplicación de tal principio únicamente se puede dar, analizando las circunstancias de cada caso particular, ya que su contenido es de naturaleza real y relacional, "es decir, que sólo se puede establecer prestando la debida consideración a las circunstancias individuales, únicas e irrepetibles de cada menor de edad"79.

De esta forma, el interés superior del niño requiere de las instituciones públicas que a la hora de tomar decisiones sobre menores de edad:

- Garanticen el desarrollo integral del menor,

- Garanticen las condiciones para el ejercicio pleno de sus derechos fundamentales,

- Brinden protección ante los riesgos prohibidos,

\footnotetext{
76 Corte Constitucional, C-507/04.

77 Convenio Adopción Internacional, preámbulo.

78 CorteI DH, serie C No 254, párr. 108, de 21 de noviembre de 2012.

79 Corte Constitucional, C-113/17.
} 
- Equilibren sus derechos con los de los padres,

- Garanticen la provisión de un ambiente familiar apto para el desarrollo del menor,

- Tengan en cuenta los elementos materiales de las relaciones de cada menor con su entorno,

- Y que sólo intervenga el Estado en las relaciones paterno materno filiales cuando existan razones poderosas que justifiquen tal intervención ${ }^{80}$.

Entonces, en la toma de decisiones los funcionarios deben evidenciar que se ha respetado el derecho al interés superior del niño ${ }^{81}$ lo cual aplica también cuando se trata de decidir sobre la adopción. Esto significa que una decisión tomada a partir de presunciones infundadas y estereotipadas sobre la capacidad e idoneidad parental de garantizar y promover el bienestar y desarrollo del niño no es apta para salvaguardar su interés superior. Por ello, para garantizar los derechos, integridad, bienestar y dignidad del menor, los procesos de adopción deben estar debidamente regulados. Según el perito Wintemute citado por la Corte Interamericana en el caso Atala Riffo vs. Chile, "la discriminación basada en la raza, la religión, el sexo o la orientación sexual del padre o la madre de un niño nunca es en el interés superior del niño" 82 . Por el contrario, una decisión que atienda dicho interés, es aquella que tiene en cuenta las cualidades de los padres; para la Corte, las consideraciones basadas en estereotipos, preconceptos o prejuicios sociales con relación a las características de las personas homosexuales o su presunto impacto en la vida de los niños y niñas, no son de recibo a la hora de decidir la adopción ${ }^{83}$. Asimismo el Tribunal Europeo de Derechos Humanos al pronunciarse sobre el caso Salgueiro Da Silva Mouta vs. Portugal, manifestó que retirar la custodia de un hijo debido a la homosexualidad del padre con el argumento de que los niños y niñas deben crecer en situaciones normales y vivir en una familia tradicional, es un acto que carece de proporcionalidad y constituye discriminación. ${ }^{84}$

"Una decisión de custodia no discriminatoria no debería referirse a la orientación sexual del padre o de la madre. Debería enfocarse solamente en las capacidades pa-

\footnotetext{
80 Corte Constitucional, C-113/17.

81 Comité de los Derechos del Niño, CRC/C/GC/14, 29 de mayo de 2013.

82 Corte IDH, serie C No 254, para. 111, de 21 de noviembre de 2012.

83 Corte IDH, serie C No 254, para. 111, de 21 de noviembre de 2012.

${ }_{84}$ TedH, Solicitud No 33290/96, para. 34-36, de 21 de diciembre de 1999.
} 
rentales del padre o de la madre, el tipo de hogar que pueden brindar, etc. No debería haber la necesidad de ni siquiera mencionar la orientación sexual" 85.

En consecuencia, la orientación sexual e identidad de género de las personas es una categoría protegida por los Derechos Humanos y cualquier norma, acto o práctica discriminatoria basada en ella estaría proscrita. "Ninguna norma, decisión o práctica de derecho interno, sea por parte de autoridades estatales o por particulares, pueden disminuir o restringir, de modo alguno, los derechos de una persona a partir de su orientación sexual" 86 . Tratándose de adopciones, si bien, todas las personas tienen derecho a iniciar el proceso y solicitar la adopción, y por lo tanto este derecho no le puede ser restringido a nadie con base en su orientación sexual o identidad de género, cuando la decisión atañe a asuntos relacionados con niños y niñas, es el interés superior del menor el que debe prevalecer ${ }^{87}$.

Así las cosas, sin importar la orientación sexual o la identidad de género de los futuros padres, ellos deben demostrar que garantizarán adecuadas condiciones de vida digna, salud y educación al menor, que asegurarán el ejercicio y disfrute pleno de sus derechos dentro del Estado, la familia y la sociedad para que se les conceda la adopción en atención al interés superior del niño y de esta manera se contribuya al desarrollo pleno e integral del menor en el seno de un hogar. Y es deber del Estado "verificar, en cada caso, si se cumplen los requisitos establecidos en el ordenamiento jurídico y la idoneidad de la familia adoptante, de tal forma que ésta brinde la estabilidad socioeconómica y un ambiente de respeto, amor y bienestar para el menor" 88 .

La adopción responde entonces al derecho de los niños y niñas a tener una familia, por ello, en el evento en que los futuros padres no se consideren adecuados para el desarrollo integral del menor los funcionarios públicos deberán probar tal situación en su decisión demostrando concretamente el daño específico y real que el vínculo tendría en el desarrollo del menor ${ }^{89}$. Así por ejemplo, la Corte de Justicia de la Nación de México, cuando decidió sobre la constitucionalidad de la adopción homoparental, estableció que "[l]a heterosexualidad no garantiza

\footnotetext{
85 Corte IDH, serie C No 254, para. 111, de 21 de noviembre de 2012, ver Expediente de fondo, tomo XI, folios 5355 y 5358 ..

86 Corte IDH, serie C No 254, para. 90, de 21 de noviembre de 2012.

87 A/Res/44/25 (1989) arts. 3 y 21.

88 Corte Constitucional, C-683/15.

89 Corte IDH, serie C No 254, párr. 125, de 21 de noviembre de 2012.
} 
que un menor adoptado viva en condiciones óptimas para su desarrollo: esto no tiene que ver con la heterosexualidad-homosexualidad. Todas las formas de familia tienen ventajas y desventajas y cada familia tiene que analizarse en lo particular, no desde el punto de vista estadístico" 90 .

Entonces, para negar una adopción por las características especiales de los futuros padres, es preciso que existan pruebas específicas que demuestren en concreto el impacto directo negativo de la conducta parental en el bienestar y desarrollo del menor ${ }^{91}$ pues "la convivencia de menores de edad con padres homosexuales no afecta per se su desarrollo emocional y psicológico" 92 . Un test de daño especulativo, es decir, aquél que se limita a hacer referencia a supuestos daños basados en eventuales situaciones de riesgo sin especificar la relación de causalidad entre la convivencia con un padre o madre homosexual y el supuesto deterioro en el desarrollo del menor, o el efecto negativo que su orientación sexual pueda tener sobre el bienestar del menor, resulta insuficiente para negar la adopción. Se requiere, por el contrario, un test estricto de análisis y sustentación de un daño concreto y específico ${ }^{93}$.

Así las cosas, no puede sostenerse a priori que la crianza por dos padres del mismo sexo, cuando ellos conforman una familia, será perjudicial para el desarrollo del menor o contraria a sus intereses y, por lo tanto, no es dable restringir genéricamente la adopción a las parejas del mismo sexo.

\section{CONCLUSIÓN}

Tratándose de la adopción, la orientación sexual o identidad de género no es condición determinante para definir la idoneidad de las personas para adoptar, por el contrario, debe estudiarse cada caso concreto en favor de garantizar que la adopción responda al interés superior del menor, teniendo en cuenta las características de cada individuo y de cada potencial familia adoptante.

La orientación sexual diversa, por sí misma, no compromete de manera negativa la salud física, mental o el desarrollo integral del menor tal como ha sido evidenciado científicamente por los estudios analizados y acogidos por los tribunales. Por el

\footnotetext{
90 Suprema Corte de Justicia A.I 2/2010, párr. 338,16 de agosto de 2010.

91 Corte IDH, serie C No 254, párr. 127, de 21 de noviembre de 2012.

92 Corte IDH, serie C No 254, párr. 128, de 21 de noviembre de 2012.

93 Corte IDH, serie C No 254, párr. 130-31, de 21 de noviembre de 2012.
} 
contrario, las afectaciones pueden producirse por causas externas consecuencia de los estereotipos y prejuicios sociales derivados de las relaciones con la comunidad antes que las derivadas del seno familiar. Así pues, los prejuicios afectan el goce y ejercicio libre y pleno de derechos, pues se constituyen en un obstáculo para su plena aplicación. Por lo tanto, los Estados tienen la obligación de tomar todas las medidas jurídicas o de otro carácter que sean necesarias para proteger a la persona y eliminar los prejuicios, las costumbres y las demás prácticas que perpetúan la desigualdad y las funciones estereotipadas del hombre, la mujer y la familia.

Si bien los prejuicios no siempre se pueden superar, sí se pueden contrarrestar, a tal punto que se acepte y se asimile la diferencia dentro de la identidad en tanto que la identidad sólo es posible gracias a la diferencia.

\section{BibLIOGRAFÍA CITADA}

Acuña-Ruiz, Andrea Elizabeth y Oyuela, Raúl (2006): "Diferencias en los prejuicios frente a la homosexualidad masculina en tres rangos de edad en una muestra de hombres y mujeres heterosexuales", en Psicología desde el Caribe (No 18), pp. 58-88.

Agencia de Derechos Fundamentales de la Unión Europea (2009): "Homofobia y discriminación por motivos de orientación sexual e identidad de género en los Estados miembros de la Unión Europea”, [fecha de consulta: 30 de enero de 2017]. [Disponible en: https://fra.europa.eu/sites/.../1224Summary-homophobia-discrimination2009_ES.pdf].

Albarracín, Mauricio y Noguera, Mauricio (2007). "Situación de los derechos humanos de lesbianas, hombres gay, bisexuales y transgeneristas en Colombia, 2006-2007", [fecha de consulta: 16 de febrero de 2017]. [Disponible en: http://colombiadiversa.org/colombiadiversa/documentos/informes-dh/ colombia-diversa-informe-dh-2006-2007.pdf].

Alonso, Ana Lucía (2014): "La influencia de los regímenes internacionales sobre los derechos de la infancia en el régimen de adopciones en México", en Revista de El Colegio de San Luis. Nueva Época (Año IV, No. 7), pp. 284-306.

Allport, Gordon (1971): La Naturaleza del Prejuicio (Buenos Aires, Editorial Eudeba).

Antezana, Marlene (2007): "Homosexualidad, familia y apoyo social", en Gaceta Médica Boliviana (V. 30, No 1), pp. 30-35.

ARdila, Rubén (2008): Homosexualidady Psicología (Santa Fe de Bogotá, Editorial Manual Moderno). 
Ardila, Rubén (2011): El Mundo de la Psicología (Santa Fe de Bogotá, Manual Moderno).

Arranz, Enrique; Martín, Juan Luis; Oliva, Alfredo y Parra, Agueda (2010): "Análisis de los problemas y necesidades educativas de las nuevas estructuras familiares" en Colegio Oficial de Psicólogos de Madrid (V 19, No 3), pp. 243251.

Baile Ayensa, José Ignacio (2008): Estudiando la homosexualidad. (Madrid, Pirámide).

Baron, Robert y Byrne, Donn (2005): Psicología Social (México, D. F., Editorial Pearson).

Barrolhet, Sergio (2007): "La pareja homosexual", en Barrolhet et al., Sobre la homosexualidad (Santiago de Chile, Editorial Mediterráneo), pp. 189-212.

BEM, Sandra Lipsitz (1981): "Gender schema theory: a cognitive account of sex typing”, en Psychological Review, (V 88, No 4) pp. 354-364.

Benedicto XVI (2009). "Fiesta de la Santa Familia de Nazaret Angelus", [fecha de consulta: 14 de mayo de 2017]. [Disponible en: https://w2.vatican.va/content/ benedict-xvi/es/angelus/2009/documents/hf_ben-xvi_ang_20091227.html].

BerTUZzI, Margarita (2007): "Familia y homosexualidad: Impacto de la homosexualidad de los padres en los hijos", en Bertuzzi et al., Sobre la homosexualidad (Santiago de Chile, Editorial Mediterráneo) pp. 213-227.

BobBio, Norberto (2010): "La naturaleza del prejuicio. Racismo, hoy. Iguales y diferentes", en CAICEDO TAPIA y PORRAS Velasco, Igualdad y no discriminación. El reto de la diversidad. (Quito, Ministerio de Justicia, Derechos Humanos y Cultos) pp. 183-215.

Bonilla, Amparo (2004): "El enfoque diferencial en el estudio del sistema sexo/ género", en Barberá y Martínez. Psicología y género (Madrid, Pearson Educación) pp. 3-34.

Bossert, Gustavo y Zannoni, Eduardo (2004): Manual de Derecho de Familia (Buenos Aires, Editorial Astrea).

Buil, Eva; García-Rubio, Estrella; Lapastora, Montse; Rabasot, Marian (2004): "La adopción por homosexuales", en Anuario de Psicología Jurídica (V 14), pp. 81-89.

CALA, María Jesús y BARBERÁ, Ester (2009): "Evolución de la perspectiva de género en psicología" en Revista Mexicana de Psicología (V 26, No 1), pp. 91-101. 
Cogam (2000). "Dossier: las familias homosexuales". [fecha de consulta: 23 de mayo de 2017]. [Disponible en: http://www.flgbiblio.org/_comun/bibliografia/pdf/cogam_2000.pdf].

Campo-Arias Adalberto; Herazo Acevedo, Edwin (2015): "La adopción por parejas del mismo sexo en Colombia”, en Revista Colombiana de Psiquiatría (V. 44, No 2), pp. 75-76.

CASTELlar, Andrés (2010): "Familia y homoparentalidad una revisión del tema", en Revista en Ciencias Sociales (No 5), pp. 45-70.

Celis Albán, Francisco (2009): Hombre con Hombre, Mujer con Mujer y Viceversa: Colombia Gay (Bogotá, Intermedio Editores).

Cuellar, Lucía; Rivera, Juan Felipe (2016). "Encuesta de clima escolar LGBT en Colombia 2016", [fecha de consulta: 2 de mayo de 2017]. [Disponible en: http://colombiadiversa.org/colombiadiversa2016/wp-content/ uploads/2016/11/IAE-Colombia-Web-FINAL-2.pdf].

Comisión Interamericana de Derechos Humanos (2015). "Violencia contra personas Lesbianas, Gay, Bisexuales, Trans e Intersex en América”, [fecha de consulta 9 de mayo de 2017]. [Disponible en: http://www.oas.org/es/cidh/ informes/pdfs/violenciapersonaslgbti.pdf].

De Irala, Jokin y López Del Burgo, Cristina (2006): "Los estudios de adopción en parejas homosexuales: mitos y falacias" en Cuadernos de Bioética (V. XVII, No 3), pp. 377-389.

Defensoría del Pueblo (2001). "Mecanismos de protección contra la violencia intrafamiliar", [fecha de consulta: 10 de junio de 2017]. [Disponible en: http:// cdim.esap.edu.co/BancoMedios/Documentos\%20PDF/mecanismos\%20 de $\% 20$ protecci\%C3\%B3n\%20contra\%20la\%20violencia\%20intrafamiliar. $\mathrm{pdf}]$

De Pablo Masa, Antonio (1976): "La Familia Española en Cambio", en Estudios sociológicos sobre la situación social de España (Madrid, Editorial Euramerica), pp. 345-405.

Estefan VARGas, Soraya (2013): “Discriminación estatal de la población LGBT. Casos de transgresiones a los Derechos Humanos en Latinoamérica", en Revista Sociedad y Economía (No 25), pp. 183-204.

Fernández Cuevas, María Patricia (2014): "Nuevas realidades entorno a la familia: familias homoparentales y la adopción” en Divulgare Boletín Científico de la Escuela Superior de Actopan (V. 1, No 1). 
Fernández ParRado, Inmaculada (2011). "La importancia de la familia en la educación infantil”, [fecha de consulta: 10 de abril de 2017]. [Disponible en: http://www.eduinnova.es/monografias2011/mar2011/familia.pdf].

FERnÁNDEZ, Juan (2004): "Perspectiva evolutiva: identidades y desarrollos de comportamientos según el género", en Barberá y Martínez, Psicología y género (Madrid, Editorial Pearson Educación) pp. 36-53.

Francisco, S. S. (2016): Sobre el Amor en la Familia (Bogotá, Ediciones Paulinas). Franke, Katherine (2007): "Los usos del sexo", en Revista de Estudios Sociales, (No 28), pp. 16-43.

García-Villanova Zurita, Félix (2005): "La adopción homoparental”, en Revista Iberoamericana de Diagnóstico y Evaluación - e Avaliação Psicológica (Año 1, No19), pp. 147-170.

Garzón-Segura, Anni Marcela (2015). "El papel del género en la psicología: una revisión desde la investigación e intervención psicológica”, [fecha de consulta: 10 de mayo de 2017]. [Disponible en: file://D:/respaldo\%2026-08-14/ Downloads/1276-2858-1-PB\%20(6).pdf].

GilberT, Herdt (2006): Homosexualidad ritual en Melanesia. (Madrid, Alcaná Libros).

Gómez Piedrahita, Hernán (1992): Derecho de Familia. (Bogotá, Editorial Temis).

Gutiérrez, Eugenio y Osorio, Paulina (2008): "Modernización y transformaciones de las familias como procesos del condicionamiento social de dos generaciones", en Última Década, ( V 16, No 29), pp.103-135.

GutiérRez SÁez, Raúl (1988): Introducción a la lógica (México, D. F., Editorial Esfinge).

HogG, Michael y Vaughan, Graham (2010): Psicología social (Madrid, Editorial Médica Panamericana).

Ibarra Barrón, Carlos (1994): Elementos fundamentales de lógica (México, D. C., Editorial Alambra).

ICBF (2014). "Concepto de carácter científico relacionado con los efectos que para el desarrollo integral de una niña, un niño o un adolescente podría tener el hecho de ser adoptado por una pareja del mismo sexo", [fecha de consulta: 10 de junio de 2017]. [Disponible en: https://www.dropbox.com/s/gc26auavcvn93o2/Concepto\%20ICBF2.pdf?dl=0].

LEÓN, Eduardo Alberto (2009): "El giro hermenéutico de la fenomenología en Martín Heidegger", en Revista Polis de la Universidad Bolivariana (V. 8, No 22), pp. 267-283. 
MarTínez Díaz, Eduardo (2012): Revelación de Dios en la realidad homosexual. Aproximación hermenéutica desde un enfoque liberador y de derechos humanos (Bogotá, Editorial USTA).

Mazeaud, Henri; Mazeaud, León y Mazeaud, Jean (1976): Lecciones de Derecho Civil (Buenos Aires, Ediciones jurídicas).

Matarazzo Boriani, Sara Alicia (2016): "La adopción en Colombia: un proceso judicial, psicológico y emocional. Reflexión a partir de una experiencia personal", en Revista de Derecho Privado (No 31), pp. 409-427.

MÉNDEZ, Víctor Hugo (2007): "Ganímedes en la Academia: la homosexualidad en las filosofías de la Grecia clásica”, en RoA et al., Sobre la homosexualidad (Santiago de Chile, Editorial Mediterráneo) pp. 15-46.

MONDIMORE, Francis Mark (1998): Una historia natural de la homosexualidad. (Barcelona: Editorial Paidós).

MujIKA, Flores, Inmaculada (2005). "Modelos familiares y cambios sociales: la homoparentalidad a debate", [fecha de consulta 12 de abril de 2017]. [Disponible en: http://www.aldarte.org/comun/imagenes/documentos/Cuaderno\%20modelos $\% 20$ familiares $\% 20 y \% 20$ cambios $\% 20$ sociales.pdf].

Myers, David (2005): Psicología Social (México, D. F., McGraw-Hill).

Oliva Gómez, Eduardo; Villa Guardiola, Vera Judith (2014): "Hacia un co. (V. 10, No 1), pp. 11-20.

OtERO BAHAMÓN, Silvia Alejandra (2008): "La iglesia como actor de la gobernanza en Colombia", [fecha de consulta: 30 de abril de 2017]. [Disponible en: http:// www.institut-gouvernance.org/es/document/fiche-document-148.html].

Pena, Mariela (2016): "La integración de niños y niñas a familias adoptivas en Argentina. Conexiones Legítimas", en Revista Latinoamericana de Ciencias Sociales, Niñez y Juventud (V. 14 , No 1), pp. 445-461.

Pineda RoA, Carlos Alejandro (2013): "Factores asociados con riesgo de suicidio de adolescentes y jóvenes autoidentificados como lesbianas, gays y bisexuales: estado actual de la literatura", en Revista Colombiana de Psiquiatría (V. 42, No 4), pp. 333-349.

Restrepo Múnera, Carolina; Sánchez Pineda, Sandra Milena; Tamayo Sepúlveda, Catalina (2010): Derecho \& Diversidad sexual. (Medellín, Sello Editorial, Universidad de Medellín).

RigGS, Damien y Due, Clemence (2014): "Gay fathers' reproductive journeys and parenting experiences: a review of research", en Journal Fam Plann Reprod health Care (V. 40, No 4), pp. 289-293. 
RoA, Armando (2007): "Fenomenología de la sexualidad humana”, en RoA et al. Sobre la homosexualidad (Santiago de Chile: Editorial Mediterráneo) pp. 15-46.

Rodríguez, Aroldo; Assmar, Eveline María; Jablonski, Bernardo (2008): Psicología Social (Bogotá, Editorial Trillas).

Rodríguez Díez, José (2006): "Indisolubilidad y divorcio en la historia del matrimonio cristiano y canónico ¿̇Indisolubilidad extrínseca relativa de futuro?”, en Anuario jurídico y económico Escurialense (No 39), pp. 171-214.

RouAst, André (1953): Evolución moderna de la adopción en Francia (Traducc. Niceto Alcalá-Zamora y Castillo), en Revista de la Facultad de Derecho de México (No 10), T. 111.

SCHENKer, Adrián (2008): “¿Por qué prohíbe la ley de Moisés la práctica del amor homosexual? Razones y alcance de una regla de vida de la Biblia”, en SCHENKer et al., Consideraciones sobre la homosexualidad en la Biblia (Madrid, Editorial Palabra) pp. 55-82.

Unicef (2003): "Nuevas formas de familia. Perspectivas nacionales e internacionales", [fecha de consulta: 24 de abril de 2017]. [Disponible en: http://files. unicef.org/uruguay/spanish/libro_familia.pdf].

Urraco-Solanilla, Mariano y Nogales-Bermejo, Gema (2013): "Michel Foucault: el funcionamiento de la institución escolar propio de la modernidad" en Revista Andaluza (No 12), pp. 153-167.

Van Der Walt, Anina y Basson, Pieter (2015): “The lived experience of discrimination of White women in committed interracial relationships with black men. Indo-Pacific", en Journal of Phenomenology (V. 15, No 2), pp. 1-16.

Vargas Trujillo, Elvia; Ripoll NúNez, Karen; Carrillo Ávila, Sonia; Rueda SÁenz, Miguel; Muñoz, John Alexander (2011): Experiencias familiares de madres y padres con orientaciones sexuales diversas. (Bogotá, Ediciones Uniandes).

\section{JURISPRUDENCIA CITADA}

Nicholas Toonen vs. Australia (1994): Comité de Derechos Humanos 4 abril 1994 Comunicación No 488/1992, U.N. Doc. CCPR/C50/D/488/1992.

Pablo Enrique Torres Gutiérrez y José Julián Prieto Restrepo (1998): Corte Constitucional de Colombia 24 marzo 1998 (acción de tutela) T-101/98 MP. Fabio Morón Díaz. 
Salgueiro Da Silva Mouta vs. Portugal (1999): Tribunal Europeo de Derechos Humanos-TEDH 21 diciembre 1999 Solicitud No 33290/96.

José Antonio Serrano Dávila (2003): Corte Constitucional de Colombia 01 abril 2003 (demanda de inconstitucionalidad contra el numeral $8^{\circ}$ del artículo 140 del Código Civil) C271/03 MP. Rodrigo Escobar Gil.

Governor in Council (2004): Supreme Court of Canada 9 diciembre 2004 (Question to the Court: same sex marriage) 2004 SCC 79.

Jesús Sanabria Ardila (2004): Corte Constitucional de Colombia 25 mayo 2004 (demanda de inconstitucionalidad contra el Código Civil, artículos 32 y 140, parciales) C-507/04 M. P. Manuel José Cepeda.

Marcela Sánchey Buitrago et al. (2007): Corte Constitucional de Colombia 7 febrero 2007 (demanda de inconstitucionalidad contra los artículos $1^{\circ} \mathrm{y}$ $2^{\circ}$, parciales, de la Ley No 54 de 1990, modificada parcialmente por la Ley No 979 de 2005) C-075/07 M. P. Rodrigo Escobar Gil.

$X$ (representado por abogado) vs. Colombia (2007): Comité de Derechos Humanos 14 mayo 2007 Comunicación No 1361/2005, U.N.Doc. CCPR/C89/ D71361/2005.

Clift vs. Reino Unido (2010): Tribunal Europeo de Derechos Humanos-TEDH 13 julio 2010 Solicitud No 7205/07.

Procurador General de la República (2010): Suprema Corte de Justicia de la Nación de México 16 agosto 2010 (acción de inconstitucionalidad artículos 146 y 319 del código civil para el distrito federal. Matrimonio entre homosexuales) A.I 2/2010 M. P. Sergio Valls Hernandez.

Carlos Andres Echeverri et al. (2011): Corte Constitucional de Colombia 26 julio 2011 (demanda de inconstitucionalidad en contra de algunas expresiones contenidas en el artículo 113 del Código Civil, en el inciso $1^{\circ}$ del artículo $2^{\circ}$ de la Ley No 294 de 1996 y en el inciso $1^{\circ}$ del artículo $2^{\circ}$ de la Ley No 1.361 de 2009) C-577/11 M. P. Gabriel Eduardo Mendoza.

Atala Riffo y niñas vs. Chile (2012): Corte IDH 21 noviembre 2012 (Solicitud de Interpretación de la Sentencia de Fondo, Reparaciones y Costas) Serie C No 254.

United States vs. Windsor (2013): United States Supreme Court 26 junio 2013 570 US Docket No 12-307.

Alejandra en representación de su hijo menor José, contra el Colegio (2013): Corte Constitucional de Colombia 23 agosto 2013 (acción de tutela) T-565/13 M. P. Luis Ernesto Vargas. 
Sergio Estrada Vélez et al. (2015): Corte Constitucional de Colombia 4 noviembre 2015 (demanda de inconstitucionalidad contra los artículos 64, 66 y 68 (parciales) de la Ley No 1.098 de 2006, "por la cual se expide el Código de Infancia y la Adolescencia”, y contra el artículo 1º (parcial) de la Ley No 54 de 1990, "por la cual se definen las uniones maritales de hecho y el régimen patrimonial entre compañeros permanentes”) C-683/15 M. P. Jorge Iván Palacio.

Chapin y Charpentier vs. Francia (2016): Tribunal Europeo de Derechos HumanosTEDH, 9 junio 2016 Solicitud No 40183/07.

Duque vs. Colombia (2016): Corte IDH 21 noviembre 2016 (Interpretación de la Sentencia de Excepciones Preliminares, Fondo, Reparaciones y Costas) Serie C No 322.

Luis Felipe Rodriges et al. (2016): Corte Constitucional de Colombia 28 abril 2016 (sentencia de unificación) SU-214/16 M. P. Alberto Rojas.

Katherinne Alejandra Velasco et al. (2017): Corte Constitucional de Colombia 22 febrero 2017 (demanda de inconstitucionalidad contra el artículo 32 (parcial) de la Ley No 1.098 de 2006 "Por la cual se expide el Código de la Infancia y la Adolescencia”) C-113/17 M. P. María Victoria Calle.

\section{NORMAS JURÍDICAS CITADAS}

Bill C-38: The civil marriage act, 20, julio de 2005, Parliament of Canada.

Convenio relativo a la Protección del Niño y a la Cooperación en materia de Adopción Internacional, 29 de mayo de 1993.

U.N. Doc. A/Res/3/217A, Declaración Universal de Derechos Humanos, Organización de Naciones Unidas, 10 de diciembre de 1948.

U.N. Doc. CCPR/C/37, Observación General No 18, No discriminación, Comité de Derechos Humanos de la ONU, 10 de noviembre de 1989.

U.N. Doc. A/Res/44/25, Convención sobre los Derechos del Niño, Organización de Naciones Unidas, 20 de noviembre de 1989.

U.N. Doc. A/Res/63/635, Declaración sobre derechos humanos, orientación sexual e identidad de género, Organización de Naciones Unidas, 22 de diciembre de 2008.

U.N. Doc. CRC/C/GC/14, Observación General No 14 sobre el derecho del niño a que su interés superior sea una consideración primordial, Comité de los Derechos del Niño de la ONU, 29 de mayo de 2013. 